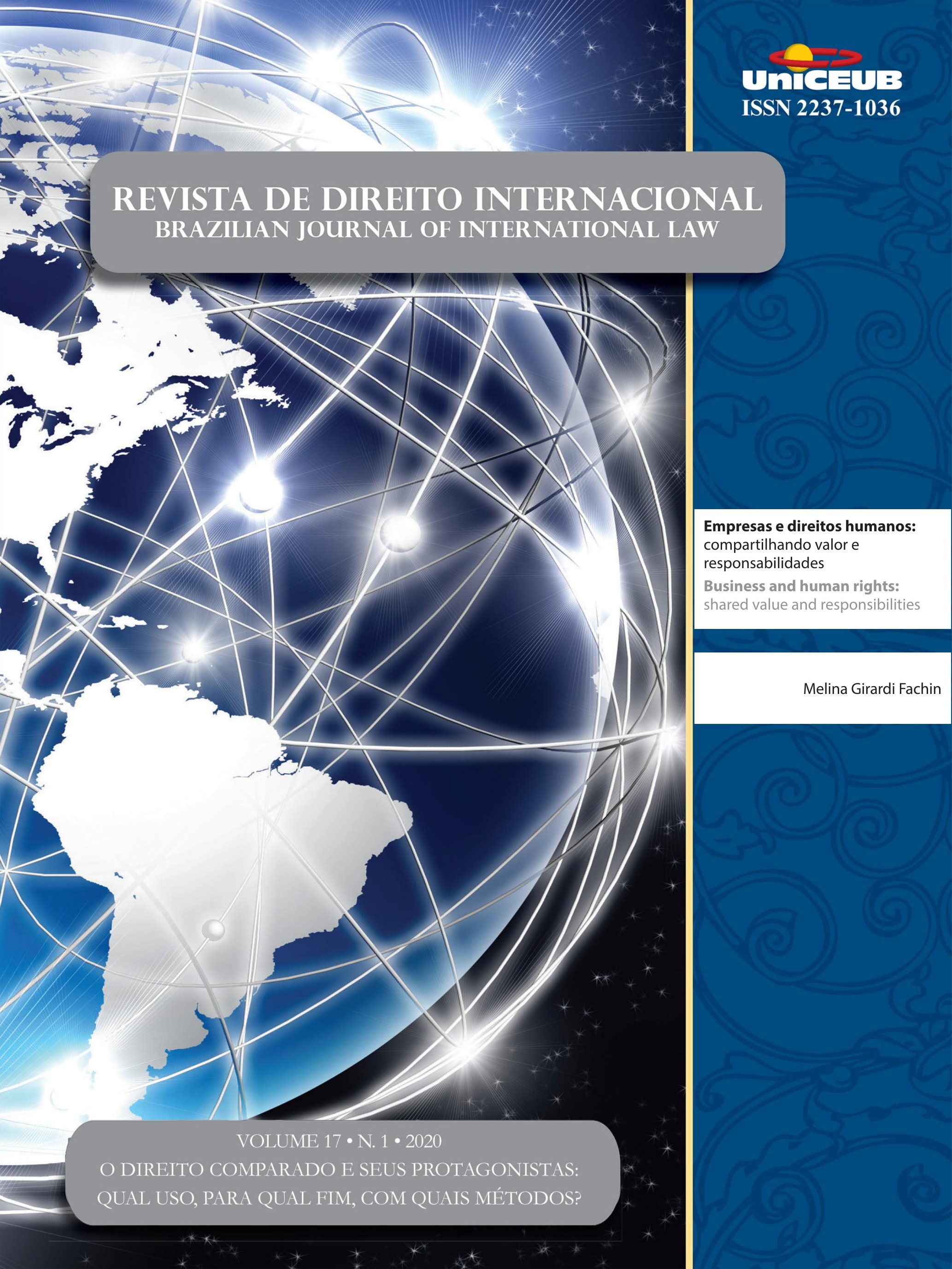


Parte I - O Direito comparado e seus Protagonistas: QuAL uso, PARA QUAL FIM, COM QUAIS MÉTODOS? .....................................................................1

EDITORIAL ............................................................................................................... 3

"Tudo o que precisamos fazer é ter certeza de que continuaremos conversando".............................. 3

Gustavo Cerqueira e Patrícia Perrone Campos Mello

Direito comparado E METOdologia $\quad$................................................... 6

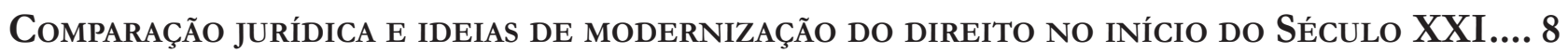
Gustavo Cerqueira

O DIREITO COMPARADO: ESFORÇO DE RESGATE HISTORIOGRÁFICO E DE PROBLEMAS METODOLÓGI$\cos$

Arnaldo Sampaio de Moraes Godoy e Gustavo Fereira Ribeiro

Direito Comparado e Política: Reflexões Necessárias .42

Raphael Carvalho de Vasconcelos e Deo Campos Dutra

Direito comparado no Brasil

L'originalité du Droit Brésilien et le Droit Comparé .57

Arnoldo Wald

LEI DA BOA RAZÃo E COMPARATISMO JURÍDICO NA DOUTRINA CIVILISTA BRASILEIRA DE 1850 A 1880

Alan Wruck Garcia Rangel

O STF EM REDE? QUANTO, COMO, COM QUE ENGAJAMENTO ARGUMENTATIVO O STF USA PRECEDENTES ESTRANGEIROS EM SUAS DECISÕES?

Patrícia Perrone Campos Mello e Felipe Meneses Graça 
Suprema Imprecisão: a metodologia em Direito Constitucional Comparado E as deficiênCias Em Seu uso pelo Supremo Tribunal Federal

Alonso Freire e Hugo Sauaia

Direitos comparados

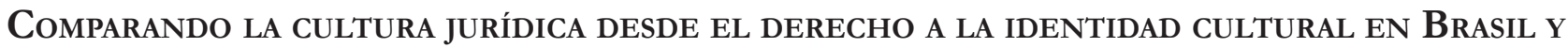

CHILE 145 Juan Jorge Faundes e Fabian Le Bonniec

O Divino e o Racional no Direito: notas para um diálogo entre sistemas jurídicos 181 Salem Hikmat Nasser e José Garcez Ghirardi

Regulação do discurso de Ódio: análise comparada em países do Sul Global 196 Jane Reis Gonçalves Pereira, Renan Medeiros de Oliveira e Carolina Saud Coutinho

Parte II - Outros temas

LA OTRA CARA DE LA MONEDA: PROTECCIÓN CONSTITUCIONAL DE LA EMPRESA, EL EMPRENDIMIENTO Y LA LIBRE COMPETENCIA EN CHILE y COLOMBiA

Juan Pablo Díaz Fuenzalida e Juan Sebastián Villamil Rodríguez

The European Court of Human Rights Decision on there 'Burqa Ban'and the CritiCal analysis of the Pragmatic experimental logic 258 Flavianne Fernanda Bitencourt Nóbrega e George Browne Rego

Direitos humanos das deslocadas ambientais e os impactos da Usina de Belo Monte: da EXPLORAÇÃO AMAZÔNICA À SUBJUGAÇÃO FEMININA

Thais Silveira Pertille e Letícia Albuquerque

Solução de Controvérsias em Acordos de Investimento: as experiênCias do CPTPP, CETA E DOS ACFIs

Fábio Morosini, Vivian Daniele Rocha Gabriel e Anastacia Costa

50 anos dos “direitos da Criança” na Convenção Americana de Direitos Humanos: a HISTÓRIA DO ARTIGO 19 311

Sven Peterke e Paloma Leite Diniz Farias 
EMPRESAS E DIREITOS HUMANOS: COMPARTILHANDO VALOR E RESPONSABILIDADES .325 Melina Girardi Fachin

CONTEMPORARY RESPONSES TO BUSINESSES' NEGATIVE HUMAN RIGHTS IMPACT 341 Andres Felipe Lopez

Human Right to LABOR PROTECTION IN UKRAINE: CURRENT SITUATION AND THE PROSPECTS OF IMPLEMENTATION OF INTERNATIONAL RULES 363 Nina Daraganova

International Regulation and Global Governance: The EU influential Method IN TIMES OF NORMATIVITY CHANGE 373 Gabriela Hühne Porto, Paula Wojcikiewicz Almeida e Juliana Maia F. A. Netto

Tecnologias digitais e o comércio de bens E SERviços na OMC/Digital. 391 Umberto Celli Junior

Los fuertes hacen lo QUe PUeden: exponiendo los límites de la Corte Penal InternaCIONAL .406

Cristián D. González-Ruiz e Víctor M. Mijares

Human Rights, Humanitarian Law and State Power 418 Renata Nagamine e João Roriz

Regional integration in the South Pacific: Challenges for Public governance .433 Joanna Siekiera

Parte III - Resenhas 443

RESENHA DA OBRA

“Democracia e policentrismo do poder", de Murilo Gaspardo 445 Angela Limongi Alvarenga Alves 


\section{Empresas e direitos humanos: compartilhando valor e responsabilidades*}

\section{Business and human rights: shared value and responsibilities}

Melina Girardi Fachin*

\section{Resumo}

O objetivo do presente artigo é fixar as premissas teóricas e os fundamentos que sustentam a responsabilidade das empresas pelos direitos humanos, forte na ideia de valor compartilhado elaborada por Porter e Kramer. Ao mesmo tempo que se busca a aferição de vantagem econômica às empresas criam-se benefícios para suprir necessidades sociais. A empreitada foi levada a cabo a partir de levantamento teórico, baseado em doutrina e documentos normativos internos e internacionais, dialogando com exemplos e business cases. A presente reflexão partiu a partir de três singelas, porém importantes perguntas sobre a temática: quais direitos? quais empresas? e por que desta vinculação? As respostas apontaram para a integralidade dos direitos e universalidade dos atores do mundo empresário, todavia não em sentido homogêneo, mas ressaltando as singularidades das totalidades. Do ponto do fundamento - o porquê - de trazer responsabilidades compartilhadas entre Estados e empresas em matéria de direitos humanos aportou-se numa tríade que perpassa pela justificativa ética, normativa e econômica, calcada sobretudo na ideia do valor compartilhado. Ao final, à guisa de conclusão, três desafios são colocados para melhor compreensão da temática, a saber: superação da ideia do Estado como único responsável; superação do antagonismo entre o mundo empresarial e a sociedade; e superação da ideia do individualismo responsivo pela responsabilidade coletiva. Ainda que o tema não seja original, a abordagem a partir das perguntas e premissas essenciais, elencando tais desafios, vinculando-se à ideia de valor compartilhado, oferecem contribuição nova sobre o tema.

Palavras-chave: Empresas e direitos humanos. Valor compartilhado. Responsabilidade social corporativa. Responsabilidade coletiva.

* Recebido em 01/08/2019

Aprovado em 20/09/2019

** Pós-Doutoranda pela Faculdade de Direito da Universidade de Coimbra. Doutora e Mestra em Direito pela Pontifícia Universidade Católica de São Paulo. Visiting Researcher na Harvard Law School. Professora dos Programas de Graduação e Pós-Graduação da Faculdade de Direito da Universidade Federal do Paraná. Coordenadora do Núcleo de Estudos em Sistemas de Direitos Humanos da Universidade Federal do Paraná (NESIDH-UFPR). Email:melinafachin@gmail.com

\section{Abstract}

The aim of this paper is to set the theoretical premises and foundations that underpin the themes of business and human rights, strong in the idea of shared value elaborated by Porter and Kramer. The analysis was carried out from a theoretical research, based on doctrine and internal and international normative documents, dialoguing with examples and business cases. This article started from three simple but important questions on the subject: which rights? which corporations? and why this attachment? The answers 
pointed to the integrality of the rights and universality of the actors of the entrepreneurial world, however not in a homogeneous sense, but emphasizing the singularities of the totalities. To respond why bringing shared responsibilities between business and human rights, a triad of ethical, normative and economic justification arose, based mainly on shared value. To conclude, three challenges are posed for a better understanding of the theme, namely: overcoming the idea of the state as sole responsible; overcoming the antagonism between the business and society; and overcoming the idea of responsive individualism, ascending the collective responsibility. Although the theme is not original, the paper's approach based on the essential questions and foundations, identifying these challenges and linking to the idea of shared value, offers an original contribution on the theme.

Keywords: Business and human rights. Shared value. Corporate social responsibility. Collective responsibility.

\section{1 À guisa de introdução}

A premissa da qual a presente reflexão parte é a necessidade da abertura da agenda dos direitos humanos para novos atores do ramo empresarial. Tradicionalmente as obrigações de direitos humanos foram pensadas contra o Estado, em especial no âmbito internacional.

Aprioristicamente reproduz-se a compreensão de que os direitos humanos se colocariam em face ou por meio do Estado. Entretanto, pela complexidade das relações sociais contemporâneas, na projeção inclusive de múltiplos espaços públicos não estatais, é necessário pensar estes direitos também em outras relações que não aquelas envolvendo agentes estatais.

Apesar de, no contexto presente, os Estados prosseguirem sendo vinculados diretamente aos direitos humanos, é necessário agregar, ao lado das responsabilidades estatais, aquelas advindas da seara privada. Isto porque o público e o Estatal hoje não encontram mais plena identidade.

O denominado Estado Pós-Social experimenta, não sem críticas ${ }^{1}$, um alargamento do campo de ação públi-

PALMER, Tom G. After the welfare state. Ottawa: Jameson Books, 2012. ca: por um lado, há a exigência de uma regulação pública da economia com maior volume e especialização; por outro, há um incremento nas responsabilidades de garantia dos bens e serviços outrora prestados diretamente pela Administração Pública.

Com o alargamento da função pública, exercida agora também por agentes privados, faz-se mister lançar luz às responsabilidades diversas vindas daquilo que juridicamente podemos chamar de função social da atividade empresária ${ }^{2}$ que encontra pouso na ideia de responsabilidade social corporativa ${ }^{3}$. Assim, desempenhar a atividade empresarial - ainda mais em países com um contexto social bastante vulnerável como é o caso do Brasil $^{4}$ - projeta-se para além do próprio negócio, tendo um valor relevante na comunidade e para com a comunidade.

Nesse sentido, quem empreende não explora apenas o seu objeto empresarial e não presta contas apenas àqueles ligados diretamente ao seu mercado; amplia-se a visão a fim de incluir nestes cuidados os "shareholders como destinatários"s. Avulta um dever de cuidado e prote-

\footnotetext{
"A função social da empresa é importante princípio e vetor para o exercício da atividade econômica, tendo em vista que o seu sentido advém da articulação entre os diversos princípios da ordem econômica constitucional. Longe de ser mera norma interpretativa e integrativa, traduz-se igualmente em abstenções e mesmo em deveres positivos que orientam a atividade empresarial, de maneira a contemplar, além dos interesses dos sócios, os interesses dos diversos sujeitos envolvidos e afetados pelas empresas, como é o caso dos trabalhadores, dos consumidores, dos concorrentes, do poder público e da comunidade como um todo. Dessa maneira, a função social da empresa contém também uma essencial função sistematizadora do ordenamento jurídico, sendo adensada por intermédio de normas jurídicas que têm por objetivo compatibilizar os diversos interesses envolvidos na atividade econômica ao mesmo tempo em que se busca a preservação da empresa e da atividade lucrativa que assim a qualifica". (FRAZÃO, Ana. Função social da empresa. In: PUCSP. Enciclopédia jurídica. Tomo direito comercial. Disponível em: https://enciclopediajuridica.pucsp.br/verbete/222/edicao-1/ funcao-social-da-empresa. Acesso em: jul. 2019.)

3 A responsabilidade social corporativa tem como marco, em 1953, a obra de Bowen: Social Responsibilities of the Businessman. O conceito é voltado à afirmação do dever de boa conduta das empresas, o que decorre de uma espécie de contrato que elas têm com a sociedade. (BOWEN, Howard G. Social responsibilities of the businessman. Estados Unidos: Iowa State University, 2013.)

4 “[...] vivemos num país injusto, com índices intoleráveis de desigualdade social, em que a opressão é capilar e onipresente. Neste quadro, o reconhecimento da vinculação direta dos particulares aos direitos fundamentais pode servir como importante instrumento para moldar, de acordo com parâmetros de justiça substancial, extraídos da Constituição, a miríade de relações assimétricas travadas na sociedade." (SARMENTO, Daniel. Direitos fundamentais e relações privadas. Rio de Janeiro: Lúmen Júris, 2004. p. 284.)

FRAZÃO, Ana. Função social da empresa. In: PUCSP. Enciclo-
} 
ção maximizado do qual nascem as shared responsabilities ${ }^{6}$ que somam responsabilidade pública e privada em relação à proteção dos direitos humanos.

O tema traz à baila o que a filósofa alemã Hannah Arendt descreveu como "responsabilidade coletiva". A despeito da complexidade do pensamento da referida autora, toma-se por empréstimo tal categoria para fixar a premissa de que há uma responsabilidade social pelo que é feito em nome e/ou em defesa da sociedade.

Não é diferente na atividade empresarial. O desenvolvimento das ações - e também o comportamento omissivo - gera consequências para inúmeras pessoas afetadas que não fazem parte diretamente do empreendimento. Vários exemplos da realidade podem ser trazidos à baila. Do ponto de vista histórico, destaca-se a colaboração privada aos regimes ditatórias na América Latina durante as décadas de 1960 e $1970 .{ }^{8}$ Do ponto de vista atual, os sucessivos desastres ambientais reforçam a atualidade e relevância da temática?

pédia jurídica. Tomo direito comercial. Disponível em: https://enciclopediajuridica.pucsp.br/verbete/222/edicao-1/ funcao-social-daempresa. . Acesso em: jul. 2019.

6 "é essencial que a cooperação internacional seja concebida não como mera caridade ou generosidade, mas como solidariedade, no marco do princípio de responsabilidades compartilhadas (shared responsibilities) na ordem global". (PIOVESAN, Flávia. Temas de direitos humanos. São Paulo: Saraiva, 2016. p. 196).

A reflexão se faz presente na obra da autora ao refletir sobre eventual culpa coletiva dos acontecimentos do povo alemão em relação à barbárie nazista. (ARENDT, Hannah. Compreender: formação, exílio e totalitarismo (ensaios). São Paulo: Cia das Letras; Belo Horizonte: EdUFMG, 2008.)

8 Em 1972, denúncias contra a empresa estadunidense International Telephone and Telegraph Company (ITT) por envolvimento no golpe militar chileno conjuntamente com tratativas junto com a agência de inteligência estadunidense, visando bloquear a eleição de Salvador Allende no Chile - pois este tinha como proposta nacionalizar a cota de $60 \%$ que possuía a empresa no Chile - deu-se passo emblemático em relação à denúncia da atuação de empresas multinacionais. In: SUBCOMMITTEE ON MULTINATIONAL CORPORATIONS. The International Telephone and Telegraph Company and Chile, 1970-7: report to the Committee on Foreing Relations United States Senate. Washington: U. S. Government Printing Office, 1973. p. 1.

9 A título ilustrativo: "Apenas 12 segundos foram suficientes para devastar Mariana com a lama tóxica contendo vários metais pesados, tais como arsênio e lítio. Houve desalojamento das populações, destruição de casas, edificações, pontes, ruas, áreas agrícolas e pastos, áreas de preservação e vegetação nativa de Mata Atlântica. A energia elétrica foi interrompida pelas hidrelétricas atingidas (Candonga, Aimorés e Mascarenhas) bem como o abastecimento de água, a pesca, o turismo, atividades escolares, dentre outras. $\mathrm{O}$ meio ambiente sofreu com mortandade de biodiversidade aquática e fauna terrestre, assoreamento dos cursos d'água e alteração dos padrões de qualidade da água doce, salobra e salgada [...]" (SALDANHA, Jania Maria Lopes; BOHRZ, Clara Rossato. Dupla influência
Se o passado remonta à ética da irresponsabilidade, calcada apenas na busca do lucro e as consequências sociais negativas vistas como efeitos colaterais inevitáveis da atividade, a partir da década de 1990, ao menos do ponto de vista normativo, a relação entre direitos humanos e empresas se estreitou. Eis o diagnóstico desta viragem paradigmática: "as oil, gas and mining companies expanded into increasingly difficult áreas, and the practice of offshore production in clothing and footware drew attention to poor working conditions in global supply chains" ${ }^{\prime \prime}$.

Nesse contexto, na arena empresarial, ao lado da legítima busca por lucro, emergem outros valores e preocupações em torno dos direitos humanos e de sua responsabilidade coletiva. O tema, que não é portanto novo, não tem passado desapercebido tanto no contexto interno quanto no contexto internacional que tem adotado, em maior ou menor grau, standarts privados de proteção e responsabilização. No âmbito internacional, por todos, citem-se os princípios Ruggie ${ }^{11}$ e no âmbito interno o recente Decreto-lei no 9.517 de 21 de novembro de 2018 que estabelece as diretrizes nacionais sobre empresas e direitos humanos - ambos abaixo melhor explicitados. O objetivo do presente artigo é explorá-los à luz da perspectiva de gênero e diversidade.

O que se busca no presente artigo é dar um novo olhar - em especial a partir da ideia de valor e responsabilidade compartilhada - ao tema. Para tanto, na primeira parte do escrito fixar-se-ão as premissas teóricas das quais partimos para falar em responsabilização das empresas por direitos humanos. Qual atividade empresária e os fundamentos de sua responsabilidade figuram a pauta temática na primeira seção. Já na segunda parte expor-se-ão os três desafios que, não únicos, mas de modo proeminente, desafiam o tema, a saber: supe-

e dupla projeção entre o local e o global: o "caso Mariana” e a (ir) responsabilidade social das empresas de mineração. Homa Pública, v. 02, n. 02, p. 159, 2018. Disponível em: http://homacdhe.com/journal/2018/10/11/dupla-influencia-e-dupla-projecao-entre-globale-local-o-caso-mariana-e-a-irresponsabilidade-social-das-empresasde-mineracao/. Acesso em: jul. 2019.)

10 UNITED NATIONS. The UN "Protect, Respect and Remedy" framework for buisness and buman rights. September 2010. Disponível em: https://www.business-humanrights.org/sites/default/files/ reports-and-materials/Ruggie-protect-respect-remedy-framework. pdf. Acesso em: nov. 2018.

11 UNITED NATIONS. Human Rights Office of the High Commissioner. Guiding principles on business and buman rights: implementing the United Nations 'Protect, Respect and Remedy' framework. (A/ HRC/17/31, 21 March 2011). 
ração do antagonismo entre o mundo empresarial e a sociedade; superação da ideia do Estado como único responsável e superação do individualismo na ética da responsabilidade. Ao longo do artigo, como auxílio de fundamentação, as shared responsibilities serão pensadas a partir de exemplos concretos vindos do próprio mercado (business cases). Tudo com base na revisão da bibliografia florescente sobre o tema que se avoluma na área.

\section{Premissas subjacentes}

Tratar da temática acerca de empresas e direitos humanos leva a uma primeira importante definição dos polos envolvidos nesta equação, ou seja: de quais direitos se trata e de quais empresas se trata? Eis o que se pretende aclarar, como premissa da discussão sobre a temática, nesta estação do artigo.

\subsection{Quais direitos?}

A pergunta acima estampada tem como resposta aquela que aponta para a universalidade dos direitos. Ou seja, todos os direitos são passíveis de responsabilização por entes privados. Neste influxo, parte-se de uma visão integral e integrada de todos os direitos.

Apreendem-se os direitos sem hierarquizá-los, estabelecendo igualdade no tratamento jurídico de ambos, reconhecendo necessariamente a imbricação existente entre todos visto que a garantia de uma categoria de direitos é condição para a observância das demais - liberdade e igualdade são faces da mesma moeda ${ }^{12}$.

Obviamente que os direitos humanos - sejam eles civis e políticos, sejam econômicos, sociais, culturais e, mais recentemente, ambientais - possuem diferenças, todavia, a visão integral dos direitos humanos assume tais diferenças para promoção de direitos, sua relação dialética de complementaridade. ${ }^{13}$ Nesta esteira erguem-

12 A respeito dessa conexão, Flávia Piovesan assevera: "Não há mais como cogitar a liberdade dissociada da justiça social, como também infrutífero pensar na justiça social dissociada da igualdade". (PIOVESAN, Flávia. Direitos bumanos e o direito constitucional internacional. 13. ed. São Paulo: Saraiva, 2012. p. 210).

13 Eis a lúcida visão de Karel Vasak, registrada há quase meio século, nesse sentido: "human rights, cultural rights have a rather curious status: They are associated either with civil and political rights (and thus, as we have seen, are considered as 'negative') or with economic and social rights (and are considered as 'positive'). They sometimes -se as lições de Amartya Sen, para quem "a privação de liberdade econômica pode gerar a privação de liberdade social e de liberdade política, assim como a privação da liberdade social ou política pode, da mesma forma, gerar a privação de liberdade econômica"14.

Eis aí a razão pela qual não se pode compactuar com a visão sectária e fragmentada de gerações ou dimensões de direitos que, por sua vez, coloca-os em diferentes patamares de exigibilidade e realização. A análise geracional ou dimensional, extremamente difundida na doutrina, leva à compartimentalização $\operatorname{arbitrária~}^{15}$ dos direitos humanos que, pelas consequências daí derivadas supra explicitadas, rompem com a visão integral e complementar da concepção contemporânea de direitos humanos.

Essa visão integrada dos direitos - sem distinção categorial - ativa o sentido da corresponsabilidade, reforçando juridicamente a tutela e aplicabilidade destes

appear in both categories of human rights in documents produced by the same Organization. They are always defined juridically as individual rights, whereas culture is essentially collective in nature, since it should be available to the whole community. In view of the uncertain status of cultural rights, they should be recognized as having a specific nature, since they are at once individual and collective." (VASAK, Karel. A 30-year struggle: the sustained effort to give force of law to the Universal Declaration of Human Rights. Disponível em: https://unesdoc.unesco.org/ark:/48223/pf0000074816. Acesso em: jun. 2018).

14 Prossegue o autor afirmando que "a privação de liberdade econômica, na forma de pobreza extrema, pode tornar a pessoa uma presa indefesa na violação de outros tipos de liberdade". (SEN, Amartya. Desenvolvimento como liberdade. São Paulo: Cia das Letras, 2000. p. 23).

15 "Poderia então ser dito que a adscrição de um direito ao catálogo de direitos civis e políticos, ou ao de direitos econômicos, sociais e culturais tem um valor heurístico, ordenador, classificatório; no entanto, uma conceitualização mais rigorosa levaria a admitir um continuum de direitos, no qual o espaço de cada direito estaria determinado pelo peso simbólico componente de obrigações positivas ou negativas nele delineadas. Por esse raciocínio, alguns direitos, claramente passíveis de serem caracterizados segundo obrigações negativas do Estado, ficam enquadrados no horizonte dos direitos civis e políticos - caso, por exemplo, da liberdade de pensamento ou da liberdade de expressão sem censura prévia. No outro extremo, alguns direitos que em sua essência se caracterizam por obrigações positivas do Estado estarão contidos no catálogo de direitos econômicos, sociais e culturais - por exemplo, o direito à moradia. No espaço intermediário entre esses dois extremos há um espectro de direitos que conjugam uma combinação de obrigações positivas e negativas, em graus diversos: identificar se um deles está na categoria dos civis e políticos, ou no grupo dos econômicos, sociais e culturais resulta de uma decisão convencional, mais ou menos arbitrária." (ABRAMOVICH, Victor. Linhas de trabalho em direitos econômicos, sociais e culturais: instrumentos e aliados. Sur Revista Internacional de Direitos Humanos, São Paulo, v. 2, n. 2, p. 194, 2005). 
aos domínios privados ${ }^{16}$. Isto posto, no âmbito negocial, convém indagar quais entidades particulares são responsáveis pela tutela dos direitos.

\subsection{Quais empresas?}

Do mesmo modo que a resposta acima dada à primeira pergunta, toda a atividade empresarial possui vinculação aos direitos humanos. Todas as empresas são, em maior ou menor medida, responsáveis por respeitar direitos.

Obviamente há uma diferença entre pequenas empresas e grandes corporações trans ou multinacionais. Todavia, isso não impede que todas sejam responsáveis e que compartilhem responsabilidades.

No plano internacional - em matéria de responsabilizações - sobressaem-se as empresas que congregam uma expressiva parcela da circulação do capital internacional - que possuem poder econômico e mesmo político para se contrapor a entes estatais e mesmo organizações internacionais - e flanam ilesas no plano das responsabilidades em termos de direitos humanos.

$\mathrm{Na}$ atualidade, as violações provocadas pelo capital empresarial transacional, que circula montas muitas vezes superiores que a receita interna de muitos Estados, restam praticamente intocadas. Enquanto, de um lado, os Estados têm sua soberania esfacelada lentamente, atores não estatais ganham força, modificando inclusive questões territoriais imbricadas à soberania daqueles. Ocorre que, por vezes, tamanho é o poderio econômico das corporações que superam os dos próprios Estados.

À guisa de exemplo, traz-se a classificação feita pela organização Global Justice Now $^{17}$ que compara as cifras de negócios das principais empresas com a renda orçamentária dos países. Osa dados são impressionantes: Segundo esta classificação, se a rede norte-americana de supermercados Walmart fosse um Estado, ocuparia o décimo posto.

Ainda, tal ranking afirma que as 25 corporações que mais faturam superam o PIB de numerosos países: por exemplo, a Amazon e a Microsof têm capital maior

\footnotetext{
16 SARMENTO, Daniel. Direitos fundamentais e relações privadas. Rio de Janeiro: Lúmen Júris, 2004. p. 334.

17 Dados disponíveis no site: https://www.globaljustice.org.uk/ sites/default/files/files/resources/corporations_vs_governments_ final.pdf. Acesso em: maio 2019.
}

que mais que Portugal, a Apple que a Bélgica, a British Petrolium que a Suíça, a Samsung que a Dinamarca, o Santander que a Colômbia, dentre várias outras comparações significativas. ${ }^{18}$

Para além do vultuoso poder econômico, as corporações possuem inúmeros privilégios estabelecidos em tratados bilaterais de investimento, recebendo o direito de processar Estados em cortes arbitrais a partir dos tratados estabelecidas. Agrava-se a situação quando o Estado em jogo é ainda um país em desenvolvimento, pois diante da necessidade de futuros investimentos para fomentar o desenvolvimento interno, quedam reféns destas congregações. ${ }^{19}$ De acordo com Bauman: "Com sua base material destruída, sua soberania e independência anuladas, sua classe política apagada, a nação-estado torna-se um mero serviço de segurança para as mega-empresas." ${ }^{20}$

A cada ano, a ONG Global Exchange divulga uma lista dos "Maiores Criminosos Corporativos" 21 para destacar as piores práticas empresariais em matéria de direitos humanos e direitos dos trabalhadores, destruição ambiental, especulação de guerra, evasão fiscal e outros crimes corporativos de colarinho branco, só para citar alguns.

Os critérios para incluir uma corporação na lista dos piores são, dentre outros: ações que afetam particularmente o sul global; má-fé da corporação; encobrimento ou ignorância dos ilícitos praticados; e oposição social às ações empresariais. A lista das companhias conta com, a título de exemplo: (i) Johnson\&Jhonson, a maior empresa de healthcare do mundo foi listada por colocar amianto em seu pó de talco, além de ocultar efeitos adversos de medicações e implantes; (ii) Monsanto/Bayer, maior vendedora de insumos agrícolas no Brasil, teve seu nome elencado por vender sementes para culturas resistentes a pesticidas (OGMs), tornando os produto-

18 Dados disponíveis no site: https://www.globaljustice.org.uk/ sites/default/files/files/resources/corporations_vs_governments_ final.pdf. Acesso em: maio 2019.

19 HOMA. Tratado sobre direitos humanos e empresas: duas questões principais. Disponível em: http://homacdhe.com/wp-content/ uploads/2015/11/Artigo-Tratado-sobre-Direitos-Humanos-eEmpresas-DuasQuest $\%$ C3\%20\%B5esPrincipais.pdfhttps://www. globaljustice.org.uk/sites/default/files/files/resources/corporations_vs_governments_final.pdf. Acesso em: mar. 2016.

20 BAUMAN, Zygmunt. Globalização: as consequências humanas. Rio de Janeiro: Zahar, 1999. p. 64.

21 Dados disponíveis no site: https:/globalexchange. org/2018/11/23/ten-top-corporate-criminals-of-2018/. Acesso em: maio 2019. 
res cada vez mais dependentes de seus produtos; (iii) Chevron - uma das maiores petrolíferas do mundo por estar fortemente envolvida com o desmatamento da amazônia na perfuração do solo na busca por combustíveis fósseis. ${ }^{22}$

Enquanto o sistema garante e promove a atividade empresarial, com economias privadas crescendo desenfreadamente, há carência de mecanismos de proteção dos indivíduos perante tais atividades, reinando a impunidade em matéria de violações de direitos humanos por empresas transnacionais. Portanto, em muito se preocupou em garantir os direitos destas empresas, que constantemente se beneficiaram às custas de atores emergentes e brechas no sistema internacional, sendo ignorados os direitos que deveriam respeitar. ${ }^{23}$

Assim, atualmente não há barreiras suficientes à atuação das corporações, sendo que possuem força suficiente para "abrir mercados, despejar povos inteiros de seus territórios, para assegurar acesso forçado a recursos naturais, liberar experiências com transgênicos, assegurar patentes de produtos e recursos naturais, etc." ${ }^{24}$ Este tem sido um ponto cego dos sistemas de proteção aos direitos humanos internacionais que não conseguem atingir diretamente os grandes agentes empresariais causadores de danos.

Muitas vezes os Estados nem conseguem fazer frente ao poderio empresarial, em especial os países do sul global, subdesenvolvidos ou em desenvolvimento, porque sofrem com a exploração interna das empresas e são condenados pela sua atividade nociva em âmbito internacional. Os efeitos do capital empresarial transnacional são, portanto, incontornáveis, influenciando instâncias governamentais nacionais e internacionais em todos os níveis, sendo que o direito internacional dos direitos humanos não pode se limitar a mera questão formal, ignorando este ponto cego que lhe acomete. ${ }^{25}$

22 Dados disponíveis no site: https://globalexchange.org/2018/11/23/ ten-top-corporate-criminals-of-2018/. Acesso em: maio 2019.

23 CARDIA, Ana Cláudia Ruy. Empresas, direitos humanos e gênero: desafios e perspectivas na proteção e no empoderamento da mulher pelas empresas transnacionais. Porto Alegre: Editora Buqui, 2015. p. 13.

24 PRIOSTE, Fernando Gallardo Vieira; HOSHINO, Thiago de Azevedo Pinheiro. Empresas transnacionais no banco dos réus: violações de direitos humanos e possibilidades de responsabilização. Curitiba: Terra de Direitos, 2009. p. 12.

25 HOMA. Tratado sobre direitos humanos e empresas: duas questões principais. Disponível em: http://homacdhe.com/wp-content/ uploads/2015/11/Artigo-Tratado-sobre-Direitos-Humanos-eEmpresas-DuasQuest $\%$ C3\%20\%B5esPrincipais.pdfhttps://www.
Esse é um lado da moeda, mas isso não isenta pequenas e médias empresas que serem responsáveis pela preservação de uma cultura de direitos humanos e diversidade. No plano interno, por exemplo, o decreto $9.517 / 2018$ refere-se diretamente às médias e grandes empresas, incluídas as empresas multinacionais com atividades no País, mas também afirma que as microempresas e as empresas de pequeno porte poderão, na medida de suas capacidades, cumprir as diretrizes fixadas.

Se todas as empresas são responsáveis por respeitar direitos humanos, não há razão para excluir as empresas de porte menor. Obviamente, ainda que nãos e sobressaiam na arena internacional, no plano interno possuem relevo e impacto.

Essa atividade empresarial não pode ficar de fora porque as micro, pequenas e médias empresas formais e informais representam mais de $90 \%$ do total de empresas e contribuem, em média, em até $70 \%$ do total de empregos e $50 \%$ do PIB. ${ }^{26}$ Portanto, é fundamental que esta expressiva parcela do setor produtivo tenha consigo a dimensão da responsabilidade que carrega. Não adianta as grandes corporações adotarem códigos de conduta, respeito aos direitos humanos e diversidade se isso não for compartilhado pela maior parte dos empregadores.

Emerge, assim, como fruto da resposta conjugada as duas primeiras perguntas que dão sentido às premissas da presente reflexão que todas as empresas são responsáveis pelo respeito aos direitos humanos compreendidos em sua dimensão holística e integral. Há, ainda, todavia, uma última pergunta que aponta para o fundamento desta afirmação que abaixo segue.

\subsection{Por quê?}

Dentre as várias direções que a presente pergunta pode suscitar, elencam-se três respostas para suportar a razão pelas quais as empresas devem engajar-se na proteção dos direitos humanos.

A primeira resposta aponta para um horizonte ético: porque é a coisa correta a fazer. Do ponto de vista humano, do ponto de vista ético, é o que sustenta o pacto

globaljustice.org.uk/sites/default/files/files/resources/corporations_vs_governments_final.pdf. Acesso em: mar. 2016.

26 Dados divulgados pelas Nações Unidas disponíveis em: https:// nacoesunidas.org/no-dia-das-micro-pequenas-e-medias-empresasonu-reconhece-jovens-empreendedores/. Acesso em: maio 2019. 
social e o próprio funcionamento da sociedade - o respeito e consideração pelo outro, seja ele como for.

Os direitos humanos possuem no seu cerne a antítese da descartabilidade do outro. A concepção contemporânea de direitos humanos exsurge, sobretudo, no plano internacional, como resposta às atrocidades totalitárias ${ }^{27}$ que marcaram o segundo grande conflito mundial.

Os regimes totalitários romperam com a associação que se tinha entre pessoa e sujeito merecedor de respeito e tutela. Apenas determinados sujeitos, com características específicas mereciam tutela. ${ }^{28} \mathrm{O}$ pós-guerra rompeu com esta dissociação, calcado na centralidade da dignidade, afirma que toda pessoa é merecedora de respeito e tutela jurídica pelo simples fato de ser pessoa. A humanidade capacita à proteção porque todos os seres humanos são portadores de dignidade intrínseca que merece guarida.

É um novo paradigma ético e jurídico focado no direito a ter direitos. ${ }^{29}$ Neste sentido nota-se, no período de reconstrução, a emergência de um discurso consti-

${ }^{27}$ O discurso da descartabilidade humana é realçado pela crença nas possibilidades ilimitadas dos sistemas totalitários, conforme alerta Hannah Arendt: "Até agora, a crença, totalitária de que tudo é possível parece ter provado apenas que tudo pode ser destruído. Não obstante, em seu afã de provar que tudo é possível, os regimes totalitários descobriram, sem o saber, que existem crimes que os homens não podem punir nem perdoar. Ao tornar-se possível, o impossível passou a ser o mal absoluto, impunível e imperdoável, que já não podia ser compreendido nem explicado pelos motivos malignos do egoísmo, da ganância, da cobiça, do ressentimento, do desejo do poder e da covardia; e que, portanto, a ira não podia vingar, o amor não podia suportar, a amizade não podia perdoar". (ARENDT, Hannah. As origens do totalitarismo. São Paulo: Cia das Letras, 1989. p. 510).

28 Sobre a dissociação protetiva entre pessoa e sujeito de direito: "O conceito de direitos humanos, baseado na suposta existência de um ser humano em si, desmoronou no mesmo instante em que aqueles que diziam acreditar nele se confrontaram pela primeira vez com seres que haviam realmente perdido todas as outras qualidades e relações específicas - exceto que ainda eram humanos. O mundo não viu nada de sagrado na abstrata nudez de ser unicamente humano." (ARENDT, Hannah. As origens do totalitarismo. São Paulo: Cia das Letras, 1989. p. 333).

29 "A calamidade dos que não têm direitos não decorre do fato de terem sido privados da vida, da liberdade ou da procura da felicidade, nem da igualdade perante a lei ou da liberdade de opinião - fórmulas que se destinavam a resolver problemas dentro de certas comunidades - mas do fato de já não pertencerem a qualquer comunidade. Sua situação angustiante não resulta do fato de não serem iguais perante a lei, mas sim de não existirem mais leis para eles; não de serem oprimidos, mas de não haver ninguém mais que se interesse por eles, nem que seja para oprimi-los". (ARENDT, Hannah. As origens do totalitarismo. São Paulo: Cia das Letras, 1989. p. 293). tucional renovado, permeado por valores e princípios - como a dignidade humana - figurando como componentes basilares dos sistemas. Por consequência, ocorre consolidação do Direito Internacional dos Direitos Humanos a partir da criação de uma base ético-normativa compartilhada.

A centralidade do princípio da dignidade humana aponta para o reencontro axiológico do direito já que o excesso de formalismo jurídico foi um dos alicerces de legalidade (em sentido estrito) que se tornou instrumento dos horrores do fascismo e do nazismo.

Essa esfera de proteção normativa e institucional dos direitos humanos ganhou contornos mais claros em 1945, com a criação da Organização das Nações Unidas $(\mathrm{ONU})$ e a elaboração da Declaração Universal dos Direitos Humanos (DUDH), em 1948. Referida Declaração é um documento emblemático na história da universalização desses direitos, uma vez que estabeleceu objetivos comuns aos Estados quanto à tutela da pessoa humana e serviu de inspiração a diversas Constituições democráticas desde então, firmando a concepção contemporânea de direitos humanos, principalmente no que tange à indivisibilidade e universalidade desses direitos.

Todavia, esta justificativa ética ainda infelizmente não tem por si só impulsionado o engajamento. Aí entra em cena a segunda justificativa pela qual empresas devem respeitar os direitos humanos: porque é lei, seja no âmbito interno, seja no plano internacional.

Destaque-se, nessa senda, o já aludido decreto 9571/2018 que estabelece as Diretrizes Nacionais sobre Empresas e Direitos Humanos. O referido diploma legislativo é na verdade coroamento de todo o trabalho colhido no campo internacional sobre a matéria.

Em 1998 foi criado, no âmbito das Nações Unidas, Grupo de Trabalho sobre Empresa Transnacionais ${ }^{30}$, que após quatro anos encaminhou uma primeira minuta das Normas de Direitos Humanos da ONU que, contudo, não foi aprovada, devido a forte oposição por parte dos representantes da atividade empresarial. ${ }^{31}$ In-

30 ANISTIA INTERNACIONAL. As normas de direitos humanos das Nações Unidas para negócios: rumo à responsabilidade legal. Reino Unido: Amnesty International Publications, 2004. p. 7.

31 UNITED NATIONS. The UN "Protect, Respect and Remedy" framework for buisness and buman rights. Disponível em: https://businesshumanrights.org/sites/default/files/reports-and-materials/Ruggieprotect-respect -remedy-framework.pdf. Acesso em: 13 nov. 2016. 
dicou-se, na mesma oportunidade, necessidade de ter-se representante especial para o tema ${ }^{32}$. Em 2005, Kofi Annan, então secretário geral, nomeou o professor de Harvard John Ruggie como Representante Especial das Nações Unidas para Empresas e Direitos Humanos.

Passada uma década da primeira iniciativa, o Conselho de Direitos Humanos acolheu o framework "Protect, Respect and Remedy" proposta por Ruggie e fundada em três pilares: i) o dever dos estados de proteger contra violações a direitos humanos por terceiros, incluindo empresas; ii) responsabilidade das empresas de respeitar direitos humanos e iii) maior acesso às vítimas a remédios efetivos, tanto judiciais quanto não judiciais. ${ }^{33}$

O mandato de John Ruggie foi renovado por novo período de três anos, finalizando em junho de 2011, culminando na aprovação dos Guiding Principles on Business and Human Rights for implementing the UN Protect, Respect and Remedy Framework - conhecidos como Princípios Ruggie que são parâmetros globais para prevenir o risco do impacto da atividade empresarial nos direitos humanos.

Tais princípios orientadores somam 31 guias, divididos em três títulos: a) O dever do Estado de proteger os direitos humanos; b) A responsabilidade das empresas de respeitar os direitos humanos e c) Acesso a mecanismos de reparação. O framework estabelecido de "Proteger, Respeitar e Reparar" norteia todo o texto.

O objetivo por detrás dos princípios é reforçar a noção de que são os estados responsáveis por monitorar as atividades das empresas atuantes em seu território, entretanto, para realiza-la é necessária a cooperação internacional entre Estados, instituições multilaterais e demais atores do direito internacional.

Insta ressaltar que a natureza dos Princípios Orientadores perante o Direito Internacional se enquadra na categoria de soft law, no sentido de que as diretrizes dispostas em seu texto não vinculam os Estados ou as empresas transnacionais que aderirem ao documento. ${ }^{34}$

32 OHCHR. Special representative of the secretary-general of human rights and transnational corporations and other business enterprises. Disponível em: https://www.ohchr.org/EN/Issues/Business/Pages/ SRSGTransCorpIndex.aspx. Acesso em: 10 nov. 2016.

33 UNITED NATIONS. The UN "Protect, Respect and Remedy" framework for buisness and human rights. Disponível em: https://businesshumanrights.org/sites/default/files/reports-and-materials/Ruggieprotect-respect -remedy-framework.pdf. Acesso em: 13 nov. 2016.

34 CARDIA, Ana Cláudia Ruy. Empresas, direitos humanos e gênero: desafios e perspectivas na proteção e no empoderamento da mulher
Portanto, a contribuição normativa dos Guiding Principles não consiste, porém, em criar novas obrigações jurídicas, mas sim orientar aos Estados sobre a aplicação de normas reconhecidas em tratados internacionais de direitos humanos já existentes e indicação de parâmetros de condutas e políticas para que as empresas não cometam violações de direitos humanos. Orientam, ademais, à adequação da legislação interna na consecução do respeito aos direitos humanos pelas empresas e da responsabilização em âmbito interno por violações desta natureza relacional.

Foi neste sentido que o mencionado decreto brasileiro datado do final do ano passado surgiu. Ele afirma que caberá às empresas, dentre outros: monitorar o respeito à direitos em sua cadeia produtiva (art. $5^{\circ}$, I); educar seus colaboradores em direitos humanos $\left(5^{\circ}\right.$, III); não violar os direitos da sua força de trabalho (art. $\left.6^{\circ}\right)$; dar condições decentes de trabalho $\left(7^{\circ}\right)$; combater a discriminação no ambiente de trabalho promovendo a valorização e o respeito à diversidade independente de gênero, orientação sexual, critério étnico-racial, origem, geracional, religioso, aparência física e de deficiência $\left(\operatorname{art.} 8^{\circ}\right)$.

Pugna, nesse influxo, pela erradicação de todas as formas de discriminação no ambiente empresarial com vistas a adotar políticas de metas percentuais crescentes de preenchimento de vagas e de promoção hierárquica para essas pessoas, contempladas a diversidade e a pluralidade, ainda que para o preenchimento dessas vagas seja necessário proporcionar cursos e treinamentos específicos (art. $8^{\circ}$, II); e expressamente dizendo que espeitar a livre orientação sexual, a identidade de gênero e a igualdade de direitos da população de lésbicas, gays , bissexuais, travestis, transexuais ou transgêneros em âmbito empresarial (art. $8^{\circ}$, IX).

Ainda assim, essa segunda justificativa também nem sempre é suficiente. Seja porque temos uma tolerância ao descumprimento normativo - as chamadas "leis que não pegam" - mas também porque ainda há a falsa ideia de que normas principiológicas não seriam diretamente aplicáveis ou não produziriam sanções pelo seu desrespeito.

Assim que se não bastasse ser a coisa certa a fazer, ou ser o que a lei dispõe, há ainda mais uma terceira

pelas empresas transnacionais. Porto Alegre: Editora Buqui, 2015. p. 165. 
razão pela qual empresas devem respeitar direitos humanos: porque é economicamente atrativo.

A adoção de padrões de direitos humanos é atrativa para o mercado e possui alta potencial de lucratividade. Cada vez mais este é um asset que as empresas buscam já que se trata de gerar riqueza e não meramente fazer filantropia uma vez que o mercado consumidor tem se tornado mais exigente e responsivo em relação a estas pautas. Por exemplo, o denominado Pink Money, movimenta 150 milhões de reais no Brasil ${ }^{35}$.

Abre-se, portanto, oportunidade de negócio significativa e interessante que tem tornado às empresas atrativo o investimento em padrões de sustentabilidade e direitos humanos. É o que Porter e Kramer rotularam de "valor compartilhado" 36 que "envolve a geração de valor econômico de forma a criar também valor para a sociedade (com o enfrentamento de suas necessidades e desafios)."

A criação de valor compartilhado ${ }^{37}$ é promotora de crescimento e dão as cores da nova governança corporativa, fomentando o que se cognomina de responsabilidade social corporativa.

Neste pormenor, convém destacar diferença significativa que há entre os parâmetros do business and human rights e a corporate social responsibility. Business in human rights possui foco nos aspectos negativos que advém da atividade empresarial, enquanto que corporate social responsability é voluntária e facada na prestação positiva.

A responsabilidade corporativa é necessariamente voluntária e surge do encorajamento de atividades guiadas a partir do seu papel social que a atividade empresária desempenha. ${ }^{38}$

De acordo Porter e Kramer, a ideia do valor compartilhado reside, de um lado, no impulsionamento de

\footnotetext{
35 Dados disponíveis na reportagem: https://www.istoedinheiro. com.br/noticias/investidores/20130531/poder-pink-money/3262. Acesso em: maio 2019.

36 PORTER, Michael E.; KRAMER, Mark R. The big idea: creating shared value: how to reinvent capitalism - and unleash a wave of innovation and growth. Harvard Business Review, n. 89, 2011.

37 PORTER, Michael E.; KRAMER, Mark R. Criação de valor compartilhado. Harvard Business Review Brasil, 6 jan. 2011. Disponível em: https://hbrbr.uol.com.br/criacao-de-valor-compartilhado/. Acesso em: jul. 2019.

38 RAMASASTRY, Anita. Corporate social responsibility versus business and human rights: bridging the gap between responsibility and accountability. Journal of Human Rights, Washington, v. 14, n. 2, p. 237-259, 2015. p. 237.
}

negócios que também produzam valor para a sociedade. $\mathrm{Na}$ definição dos próprios autores:

\begin{abstract}
A solução está no princípio do valor compartilhado, que envolve a geração de valor econômico de forma a criar também valor para a sociedade (com o enfrentamento de suas necessidades e desafios). É preciso reconectar o sucesso da empresa ao progresso social. Valor compartilhado não é responsabilidade social, filantropia ou mesmo sustentabilidade, mas uma nova forma de obter sucesso econômico. Não é algo na periferia daquilo que a empresa faz, mas no centro. E, a nosso ver, pode desencadear a próxima grande transformação no pensamento administrativo. ${ }^{39}$
\end{abstract}

Caso digno de nota pelos autores é da Nespresso - marca da suíça Nestlé de capsulas de café. A Nespresso passou a adquirir sua matéria prima (café) de pequenos agricultores, geralmente localizados em áreas subdesenvolvidas marcadas pela baixa produtividade, baixa qualidade e degradação ambiental. Na tentativa de criar valor compartilhado, a Nestle treinou os produtores para melhores práticas agrícolas; proteção das plantas com manejo de fertilizantes e pesticidas; incentivou com prêmio a produção de grãos melhores. Essas ações geraram aumento da renda dos produtores, diminuição do impacto ambiental do cultivo e, também, gerou um melhor café fornecido à empresa que aumenta a sua margem de lucro. ${ }^{40}$

Acerca do retorno econômico desta preocupação social, afirmam Porter e Kramer:

Nem todo lucro é igual — ideia que se perdeu no foco estreito e imediatista do mercado financeiro e em muito do pensamento administrativo. O lucro que envolve um propósito social é uma forma superior de capitalismo - forma que permitirá à sociedade avançar mais rapidamente e, a empresas, crescer ainda mais. ${ }^{41}$

O valor compartilhado tem o potencial de remodelar os negócios, a economia e sua relação com a sociedade. ${ }^{42}$ Pela ótica do valor compartilhado, e seu impacto

39 PORTER, Michael E.; KRAMER, Mark R. Criação de valor compartilhado. Harvard Business Review Brasil, 6 jan. 2011. Disponível em: https://hbrbr.uol.com.br/criacao-de-valor-compartilhado/. Acesso em: jul. 2019.

40 PORTER, Michael E.; KRAMER, Mark R. The big idea: creating shared value: how to reinvent capitalism - and unleash a wave of innovation and growth. Harvard Business Review, n. 89, 2011.

${ }^{41}$ PORTER, Michael E.; KRAMER, Mark R. Criação de valor compartilhado. Harvard Business Review Brasil, 6 jan. 2011. Disponível em: https://hbrbr.uol.com.br/criacao-de-valor-compartilhado/. Acesso em: jul. 2019.

42 PORTER, Michael E.; KRAMER, Mark R. Criação de valor compartilhado. Harvard Business Review Brasil, 6 jan. 2011. Disponível 
econômico de retorno aos negócios, impulsiona-se o respeito das empresas aos standarts de direitos humanos.

Portanto, seja pelo aspecto ético, pelo plano legal ou pelo fator econômico, certo é que o respeito aos direitos humanos é benéfico à atividade empresarial. Não há, então, juízo de valor nas justificativas elencadas que não se excluem. Se puder ser um ganha/ganha - em termos de lucros e direitos humanos, tanto melhor.

\section{Desafios desta nova realidade: superação}

Para levar adiante esta nova lógica de responsabilidade pelos direitos humanos é necessário construir um novo mindset de um "capitalismo superior" ${ }^{43}$, na expressão de Porter e Kramer que ao invés de externalidades ${ }^{44}$, veem nas necessidades sociais oportunidades de crescimento e geração de novos negócios e lucro.

Todavia, para tanto faz-se mister enfrentar alguns desafios implicados nesta mudança de apreensão. Aqui elencam-se três principais reptos para tanto, a saber: superação da ideia do Estado como único responsável; superação do antagonismo entre o mundo empresarial e a sociedade; e superação da ideia do individualismo responsivo.

em: https://hbrbr.uol.com.br/criacao-de-valor-compartilhado/. Acesso em: jul. 2019.

43 "O capitalismo é um veículo inigualável para a satisfação das necessidades humanas, o aumento da eficiência, a criação de emprego e a geração de riqueza. Só que uma concepção estreita do capitalismo impediu que a atividade empresarial explorasse todo seu potencial para enfrentar os grandes desafios da sociedade. As oportunidades sempre estiveram aí, mas foram negligenciadas. Uma empresa atuando como empresa, não como um ente filantrópico, é o agente mais forte para lidar com as prementes questões a nossa frente. O momento para uma nova concepção do capitalismo é agora; as necessidades da sociedade são grandes e seguem crescendo. Já clientes, trabalhadores e uma nova geração de jovens estão pedindo que o meio empresarial tome a dianteira." (PORTER, Michael E.; KRAMER, Mark R. Criação de valor compartilhado. Harvard Business Review Brasil, 6 jan. 2011. Disponível em: https://hbrbr.uol.com. br/criacao-de-valor-compartilhado/. Acesso em: jul. 2019.)

44 "surgem externalidades quando a empresa gera custos sociais com os quais não precisa arcar, como a poluição. Logo, a sociedade deve impor impostos, normas e sanções para que a empresa "internalize" essas externalidades — crença que influencia muitas políticas públicas." (PORTER, Michael E.; KRAMER, Mark R. Criação de valor compartilhado. Harvard Business Review Brasil, 6 jan. 2011. Disponível em: https://hbrbr.uol.com.br/criacao-de-valor-compartilhado/. Acesso em: jul. 2019.)

\subsection{Superação da ideia do Estado como único responsável}

As normas de direitos humanos são tradicionalmente lidas como destinadas aos Estados, devido ao fato de terem sido, e até hoje o são, os maiores violadores de direitos humanos, mas isso não deve eximir de se refletir sobre novas e importantes formas de violação.

Por exemplo, no preâmbulo da DUDH consta: "Considerando que os Estados membros se comprometeram a promover, em cooperação com a Organização das Nações Unidas, o respeito universal e efetivo dos direitos do Homem e das liberdades fundamentais". A Constituição Brasileira é a norma proeminente do Estado. Resta evidente que a arquitetura internacional está baseada numa perspectiva "estatocêntrica", ainda que com contornos de soberanias relativizadas e diálogos recíprocos entre as ordens nacionais e internacional.

É o Estado, por meio de seus poderes Executivo, Legislativo e Judiciário, que é visto como o principal cumpridor (ou violador) da agenda dos direitos humanos.

Em matéria de direitos humanos está-se localizado inegavelmente ainda no paradigma estatocêntrico da responsabilidade. Todavia, este quadro não atende mais à complexidade contemporânea das violações de direitos.

A Corte Interamericana de Direitos Humanos, em sua Opinião Consultiva no $18 / 03$, embora não tenha se manifestado acerca da responsabilização internacional das empresas, referiu-se à "eficácia horizontal dos direitos humanos", imputando aos Estados o dever de assegurarem que os atores privados respeitem os direitos humanos. ${ }^{45}$

No plano interno a ideia de eficácia horizontal, ou inter privada, de direitos humanos caminha bem. Ainda que não haja lei absolutamente explícita sobre o assunto - e tal não se faz necessário - a jurisprudência dos Tribunais está recheada de exemplos em que particulares são condenados por violações de direitos humanos.

$\mathrm{Na}$ justiça do trabalho, por exemplo, há condenações por violações à funcionários discriminados por seus chefes por razões de raça - o segurança apelidado

45 INTERAMERICAN COURT H. R. Juridical condition and rights of the undocumented migrants. Advisory Opinion OC-18/03, September 17, 2003, paras. 140, 147 and 150. 
de "negão"46; de gênero - diferença salarial deliberada entre homens e mulheres ${ }^{47}$; de aparência - a cozinheira chamada de "gorda" vista tratamento vexatório no âmbito laboral ${ }^{49}$, só para citar alguns exemplos.

Assim que - ainda com as dificuldades impostas pela cultura que vê na diferença fator de diminuição e não de promoção - juridicamente caminha-se para uma resposta - no Judiciário - de limite ao abuso.

O desafio que se coloca, no plano internacional, é superar a limitação atual do direito internacional para que os indivíduos possam litigar contra empresas transnacionais que provocam massivas violações de direitos humanos em Estados muitas vezes pobres. Nestes casos as vulnerabilidades se somam, porque além das vítimas, os Estados com dificuldades socioeconômicas, reféns do sistema de dominação do capital financeiro internacional, não possuem poder em face das grandes corporações.

O afastamento desta visão do Estado como único responsável leva ao próprio repensar das fronteiras entre o espaço público e privado desenhados e ao segundo desafio posto.

\subsection{Superação do antagonismo entre o mundo empresarial e a sociedade}

Com uma visão bastante moderna da cisão entre público e privado, ainda há o repto de se superar a visão de que cabe às empresas buscar apenas o lucro e que ao Estado - quando muito ao terceiro setor - caberia a solução de problemas sociais.

Não se sustenta mais, ao menos de modo preciso, a distinção $0^{50}$ entre o jardim e a praça, no dizer de Nelson

46 BRASIL. Tribunal Superior do Trabalho. ARR-42471.2010.5.09.001.0016. Relator Ministro Ministro Alberto Luiz Bresciani de Fontan Pereira. Publicado no DJE 164/06/2013.

47 MUNIZ, Mariana. Juiz do trabalho condena empresa por pagar deliberadamente menos às mulheres. Jota. Disponível em: https:// www.jota.info/paywall? redirect_to=//www.jota.info/tributos-eempresas/trabalho/juiz-do-trabalho-condena-empresa-por-pagardeliberadamente-menos-as-mulheres-09082018.\%20Acesso $\% 20$ em $\% 20$ agosto $\% 20$ de $\% 202018$. Acesso em: ago. 2018.

48 OLIVEIRA, Mariana. TST condena empresa a indenizar em R \$ 30 mil cozinheira chamada de gorda pela chefe. Globo. Economia. Disponível em: https://g1.globo.com/economia/noticia/2018/10/03/ tst-condena-empresa-a-indenizar-em-r-30-mil-cozinheira-chamadade-gorda-pela-chefe.ghtml. Acesso em: maio 2019.

49 BRASIL. Tribunal Superior do Trabalho. ARR-42471.2010.5.09.001.0016. Relator Ministro Ministro Alberto Luiz Bresciani de Fontan Pereira. Publicado no DJE 164/06/2013.

50 "Nadie en su sano juicio puede pretender la desaparición de la
Saldanha ${ }^{51}$. Não há mais fronteira aguda que aparte a sociedade dos entes privados. Este tradicional império dos indivíduos, àquele do Estado.

É nesse paradoxal terreno que abrolha a problemática da responsabilidade pelos direitos humanos às empresas. A vinculação dos particulares aos direitos bem demonstra a falácia da dicotomia antagônica entre público e privado, social e empresarial, somam-se em direção à realização das necessidades humanas. Em outras palavras, "público e privado são, na unidade teleológica dos interesses universalizáveis, uma mesma e unia realidade, nascida dos mesmos princípios e votada aos mesmos fins: um é a vida do outro." 52

Imputar às empresas a responsabilidade de arcar com demandas sociais é vista como uma externalidade, nos termos acima postos, e corresponderia, na visão capitalista tradicional, em aumento de custos e redução de lucros. Ainda hoje a responsabilidade social corporativa é vista como uma resposta às pressões externas para melhorar a reputação da empresa e são tratados como um gasto necessário e não como uma possibilidade de investimentos.

Faz-se mister superar, portanto, essa ordem de ideias. Não se trata de filantropia ou de custos, mas sim de uma nova forma de encarar a atividade empresária e o próprio lucro. A saber:

O valor compartilhado faz a empresa se concentrar
no lucro certo: o lucro que gera - em vez de
reduzir - benefícios para a sociedade. O mercado
de capitais sem dúvida seguirá fazendo pressão para
que empresas deem lucro a curto prazo, e certas
empresas certamente seguirão registrando lucro
à custa de necessidades da sociedade. Só que esse
lucro em geral terá curta duração; oportunidades
muito maiores serão perdidas.

O momento para uma visão ampliada da geração de valor chegou. Uma série de fatores, como a crescente conscientização social de trabalhadores e cidadãos e a

frontera entre las dos esferas, la publica y la privada, porque la invasíon de la sociedad por el Estado, la abolicion de la esfera privada, es justamente el rasgo más característico de um régimen totalitário. Pero no puede negarse que esa frontera se há ido difuminando, es cada vez menos nítida.” In: BILBAO UBILLOS, Juan Maria. ¿En qué medida vinculan a los particulares los derechos fundamentales? In: SARLET, Ingo Wolfgang. Constituição, direitos fundamentais e direito privado. Porto Alegre: Livraria do Advogado, 2003. p. 305.

51 SALDANHA, Nelson. O jardim e a praça. São Paulo: Edusp, 2003.

52 PASQUALINI, A. O público e o privado. In: SARLET, I. W. (org.). O direito público em tempos de crise: estudos em homenagem a Ruy Rubem Ruschel. Porto Alegre: Livraria do Advogado, 1999. p. 36. 
crescente escassez de recursos naturais, abrirá oportunidades sem precedentes para a geração de valor compartilhado.

Precisamos de uma forma mais sofisticada de capitalismo — forma imbuída de um propósito social. Mas esse propósito não deve surgir da caridade, mas de um entendimento mais profundo da concorrência e criação de valor econômico. Essa próxima evolução do modelo capitalista reconhece novas e melhores maneiras de desenvolver produtos, atender a mercados e erguer empreendimentos produtivos.

Para, entretanto, abraçar esta ideia há que se retornar ao ponto inicial aqui posto da responsabilidade coletiva e a ruptura do individualismo social reinante, herança do projeto (jurídico) moderno.

\subsection{Retomada da responsabilidade individual e coletiva: EU + UM + UM... ${ }^{53}$}

A ideia de que empresas e sociedades conflitem exige a visão de que estas estariam fora da sociedade. Isto decorre na verdade de uma visão individualista que tem na sua origem individualismo metodológico na abordagem da questão.

Nesse sentido, adverte Alexandre Pasqualini: Indivíduo e sociedade: tais são os dois principais
ângulos da geografia humana. Esses dois ângulos
são, ao mesmo tempo, as suas duas necessidades
(ananke). Uma não existe sem a outra. Mas há duas
guerras nestas duas fronteiras: a guerra da opressão,
que é a preponderância do Estado sobre o indivíduo;
a guerra do individualismo, que é a supremacia do
indivíduo sobre o Estado. Dois excessos de um
único erro: falta de identidade moral entre ambos.

A jornalista Eliane Brum, em coluna rceente no jornal El País, trouxe a voz do poeta Elio Alves da Silva. Ele era pescador, até o surgimento de Belo Monte e disse à jornalista: "Eu, sozinho, não consigo nada. Mas, se eu for ali e chamar mais um, vai ser eu+um. Aí, esse um chama +um. E aí já é eu+um+um..." ${ }^{55}$

\footnotetext{
53 BRUM, Eliane. $\mathrm{EU}+\mathrm{UM}+\mathrm{UM}+\mathrm{UM}+$ : a responsabilidade de cada um na luta contra a destruição do Brasil. El País. Disponível em: https://brasil.elpais.com/brasil/2019/05/15/politica $\% 20$ /1557921007_146962.html. Acesso em: jul. 2019.

54 PASQUALINI, A. O público e o privado. In: SARLET, I. W. (org.). O direito público em tempos de crise: estudos em homenagem a Ruy Rubem Ruschel. Porto Alegre: Livraria do Advogado, 1999. p. 36.

55 BRUM, Eliane. $\mathrm{EU}+\mathrm{UM}+\mathrm{UM}+\mathrm{UM}+$ : a responsabilidade de cada um na luta contra a destruição do Brasil. El País. Disponível em: https://brasil.elpais.com/brasil/2019/05/15/politica $\% 20$ /1557921007_146962.html. Acesso em: jul. 2019.
}

O modelo de desenvolvimento econômico e social, calcado no individualismo, trata o tum como algo de menor sentido ou valor. Na expressão de Zygmunt Bauman, "o Estado sabe que estou estatisticamente presente, mas também sabe que eu só conto como um e não tenho capacidade de me somar aos outros. ${ }^{.56}$

Por isso ser mais um não importa, apenas teria relevo para os assuntos daquele um. Mutatis mutandis a empresa importaria para ela e não para o seu entorno social e os direitos humanos aí implicados.

Todavia, alerta Brum, "Ser +um é ser junto com o outro, é ser na comunidade, é exercer a solidariedade, é fazer soma para ser mais forte conjugando o coletivo." ${ }^{.57}$ Avulta o papel essencial da cooperação, por parte dos Estados, empresas, sociedade e indivíduos, em cumprir com seus deveres, separada e conjuntamente, para alcançar a plena realização desses direitos. Do ponto de vista individual, a Declaração Universal de 1948 já anunciava esta perspectiva em seu artigo 22. ao descrever o somatório do esforço nacional e da cooperação internacional na proteção da dignidade.

$\mathrm{Na}$ busca desse mínimo compartilhado importa a advertência de Peter Häberle ${ }^{58}$, no que diz respeito ao contexto coletivo da dignidade da pessoa humana ${ }^{59}$. Rompe-se com a ideia de que a dignidade é inata ao ser humano já que somos com o outro, na relação com o outro, e, portanto, a dignidade surge justamente desta interação, do +um. Nas palavras de Brum, "Ser +um é ser na relação com outro. Ser + um é saber que todos os outros importam., 60

56 BAUMAN, Zygmunt; MAURO, Ezio. Babel: entre a incerteza e a esperança. Rio de Janeiro: Zahar, 2016.

57 BRUM, Eliane. EU + UM + UM + UM+: a responsabilidade de cada um na luta contra a destruição do Brasil. El País. Disponível em: https://brasil.elpais.com/brasil/2019/05/15/politica $\% 20$ /1557921007_146962.html. Acesso em: jul. 2019.

58 HABERLE, Peter. A dignidade humana como fundamento da comunidade estatal. In: SARLET, Ingo Wolfgang (org.). Dimensões da dignidade: ensaios de filosofia do direito e direito constitucional. 2. ed. Porto Alegre: Livraria do Advogado, 2009.

59 "Há quem aponte para o fato de que a dignidade da pessoa humana não deve ser considerada exclusivamente como algo inerente à natureza do homem (no sentido de uma qualidade inata), na medida que a dignidade também possui um sentido cultural, sendo fruto do trabalho de diversas gerações da humanidade em seu todo, razão pela qual a dimensão natural e a dimensão cultural da dignidade da pessoa humana se complementam e interagem mutuamente." (SARLET, Ingo Wolfgang. Eficácia dos direitos fundamentais. Porto Alegre: Livraria do Advogado, 1998. p. 105).

60 BRUM, Eliane. EU + UM + UM + UM+: a responsabilidade de cada um na luta contra a destruição do Brasil. El País. Disponív- 
A superação do individualismo metodológico, a recuperação do valor imprescindível que cada ser humano possui e a capacidade emancipatória da ação coletiva somam-se ao mantra dos direitos humanos que "têm como valor fundante a solidariedade, que, em uma ordem cada vez mais global, invoca o dever de cooperação" ${ }^{\prime 1}$.

\section{Breves notas conclusivas}

Percorrido o singelo percurso proposto ao presente trabalho impende findar. Acaba-se chegando ao paradoxo onde o concluir ganha sabor de começo.

Eis aí a principal conclusão desse parco artigo: ainda principiamos. Está-se no início do desenvolvimento da florescente e instigante temática da responsabilidade das empresas em relação aos direitos humanos.

Os polos desta relação já estão um pouco mais definidos. Toda a atividade empresária, dentro de suas especificidades, é responsável pela realização de toda a miríade de direitos humanos no que for cabível e possível.

A ideia de valor compartilhado é o guia que fundamenta essa nova ordem de ideias já que as empresas, ao perquirir lucro, podem obtê-lo ou maximizá-lo na medida que atendem aos direitos humanos da comunidade e sociedade na qual estão inseridas.

Assim que, para prosseguir em frente na discussão da incidência dos direitos e de sua responsabilidade às corporações empresariais, recolhendo os melhores frutos da doutrina, o trabalho aponta para três desafios principais que servem de bússola diante do porvir incerto:

O primeiro deles é que o Estado não é mais o único responsável pela realização e proteção de tais direitos.

A segunda premissa guia é o papel central que as empresas hoje possuem no contexto social, ainda mais nos vulneráveis, gerando e agregando valor.

Por fim, a derradeira reminiscência toca à superação do individualismo e o reconhecimento da responsabili-

el em: https://brasil.elpais.com/brasil/2019/05/15/politica \%20 /1557921007_146962.html. Acesso em: jul. 2019.

61 PIOVESAN, Flávia. Proteção dos direitos sociais: desafios do ius commune sul-americano. Revista de Estudos Constitucionais, Hermenêutica e Teoria do Direito (RECHTD), São Leopoldo, v. 3, n. 2, p. 217, jul./dez. 2011. Disponível em: http://www.rechtd.unisinos.br/ pdf/\%20122.pdf. Acesso em: abr. 2012. dade pelo outro, que clamam a responsabilidade coletiva pela realização das necessidades humanas.

\section{Referências}

ABRAMOVICH, Victor. Linhas de trabalho em direitos econômicos, sociais e culturais: instrumentos e aliados. Sur Revista Internacional de Direitos Humanos, São Paulo, v. 2, n. 2, 2005.

ARENDT, Hannah. As origens do totalitarismo. São Paulo: Cia das Letras, 1989.

ARENDT, Hannah. Compreender: formação, exílio e totalitarismo (ensaios). São Paulo: Cia das Letras; Belo Horizonte: EdUFMG, 2008.

ANISTIA INTERNACIONAL. As normas de direitos bumanos das Nações Unidas para negócios: rumo à responsabilidade legal. Reino Unido: Amnesty International Publications, 2004.

BAUMAN, Zygmunt. Globalização: as consequências humanas. Rio de Janeiro: Zahar, 1999.

BAUMAN, Zygmunt; MAURO, Ezio. Babel: entre a incerteza e a esperança. Rio de Janeiro: Zahar, 2016.

BILBAO UBILLOS, Juan Maria. ¿En qué medida vinculan a los particulares los derechos fundamentales? In: SARLET, Ingo Wolfgang. Constituição, direitos fundamentais e direito privado. Porto Alegre: Livraria do Advogado, 2003.

BOWEN, Howard G. Social responsibilities of the businessman. Estados Unidos: Iowa State University, 2013.

BRASIL. Tribunal Superior do Trabalho. ARR-42471.2010.5.09.001.0016. Relator Ministro Ministro Alberto Luiz Bresciani de Fontan Pereira. Publicado no DJE 164/06/2013.

BRUM, Eliane. EU + UM + UM + UM+: a responsabilidade de cada um na luta contra a destruição do Brasil. El País. Disponível em: https://brasil.elpais.com/ brasil/2019/05/15/politica\%20/1557921007_146962. html. Acesso em: jul. 2019.

CARDIA, Ana Cláudia Ruy. Empresas, direitos humanos e gênero: desafios e perspectivas na proteção e no empoderamento da mulher pelas empresas transnacionais. Porto Alegre: Editora Buqui, 2015.

FRAZÃO, Ana. Função social da empresa. In: PUCSP. 
Enciclopédia jurídica. Tomo direito comercial. Disponível em: https://enciclopediajuridica.pucsp.br/verbete/222/edicao-1/funcao-social-da-empresa. Acesso em: jul. 2019.

HABERLE, Peter. A dignidade humana como fundamento da comunidade estatal. In: SARLET, Ingo Wolfgang (org.). Dimensões da dignidade: ensaios de filosofia do direito e direito constitucional. 2. ed. Porto Alegre: Livraria do Advogado, 2009.

HOMA. Tratado sobre direitos humanos e empresas: duas questões principais. Disponível em: http://homacdhe. com/index.php/pt/documentos/. Acesso em: mar. 2016.

INTERMAERICAN COURT H. R. Juridical condition and rights of the undocumented migrants. Advisory Opinion OC-18/03, September 17, 2003.

MUNIZ, Mariana. Juiz do trabalho condena empresa por pagar deliberadamente menos às mulheres. Jota. Disponível em: https://www.jota.info/. Acesso em: ago. 2018.

OHCHR. Special representative of the secretary-general of buman rights and transnational corporations and other business enterprises. Disponível em: http://www.ohchr.org/EN/ Issues/Business/Pages/SRSGTransCorpIndex.aspx. Acesso em: 10 nov. 2016.

OLIVEIRA, Mariana. TST condena empresa a indenizar em R \$30 mil cozinheira chamada de gorda pela chefe. Globo. Economia. Disponível em: https://g1.globo. com/economia/noticia/2018/10/03/tst-condena-empresa-a-indenizar-em-r-30-mil-cozinheira-chamada-degorda-pela-chefe.ghtml. Acesso em: maio 2019.

PALMER, Tom G. After the welfare state. Ottawa: Jameson Books, 2012.

PASQUALINI, Alexandre. O público e o privado. In: SARLET, Ingo Wolfgang. (org). O direito público em tempos de crise: estudos em homenagem a Ruy Rubem Ruschel. Porto Alegre: Livraria do Advogado, 1999.

PIOVESAN, Flávia. Direitos humanos e o direito constitucional internacional. 13. ed. São Paulo: Saraiva, 2012.

PIOVESAN, Flávia. Proteção dos direitos sociais: desafios do ius commune sul-americano. Revista de Estudos Constitucionais, Hermenêutica e Teoria do Direito (RECHTD), São Leopoldo, v. 3, n. 2, p. 217, jul./dez. 2011. Disponível em: http://www.rechtd.unisinos.br/pdf/\%20 122.pdf. Acesso em: abr. 2012.
PIOVESAN, Flávia. Temas de direitos humanos. São Paulo: Saraiva, 2016.

PORTER, Michael E.; KRAMER, Mark R. The big idea: creating shared value: how to reinvent capitalism - and unleash a wave of innovation and growth. Harvard Business Review, n. 89, 2011.

PORTER, Michael E.; KRAMER, Mark R. Criação de valor compartilhado. Harvard Business Review Brasil, 6 jan. 2011. Disponível em: https://hbrbr.uol.com.br/ criacao-de-valor-compartilhado/. Acesso em: jul. 2019.

PRIOSTE, Fernando Gallardo Vieira; HOSHINO, Thiago de Azevedo Pinheiro. Empresas transnacionais no banco dos réus: violações de direitos humanos e possibilidades de responsabilização. Curitiba: Terra de Direitos, 2009.

RAMASASTRY, Anita. Corporate social responsibility versus business and human rights: bridging the gap between responsibility and accountability. Journal of $\mathrm{Hu}$ man Rights, Washington, v. 14, n. 2, 2015.

SALDANHA, Jânia Maria Lopes; BOHRZ, Clara Rossato. Dupla influência e dupla projeção entre o local e o global: o "caso Mariana" e a (ir)responsabilidade social das empresas de mineração. Homa Pública, v. 02, n. 02, p. 159, 2018. Disponível em: http://homacdhe.com/ journal/pt/edicoes/. Acesso em: jul. 2019.

SALDANHA, Nelson. O jardim e a praça. São Paulo: Edusp, 2003.

SARLET, Ingo Wolfgang. Eficácia dos direitos fundamentais. Porto Alegre: Livraria do Advogado, 1998.

SARMENTO, Daniel. Direitos fundamentais e relações privadas. Rio de Janeiro: Lúmen Júris, 2004.

SEN, Amartya. Desenvolvimento como liberdade. São Paulo: Cia das Letras, 2000.

SUBCOMMITTEE ON MULTINATIONAL CORPORATIONS. The International Telephone and Telegraph Company and Chile, 1970-7: report to the Committee on Foreing Relations United States Senate. Washington: U. S. Government Printing Office, 1973.

UNITED NATIONS. The UN "Protect, Respect and Remedy" framework for buisness and human rights. September 2010. Disponível em: https://www.business-humanrights.org/sites/default/files/reports-andmaterials/Ruggie-protect-respect-remedy-framework. pdf. Acesso em: nov. 2018. 
UNITED NATIONS. Human Rights Office of the High Commissioner. Guiding principles on business and buman rights: implementing the United Nations 'Protect, Respect and Remedy' framework. (A/HRC/17/31, 21 March 2011).

VASAK, Karel. A 30-year struggle: the sustained effort to give force of law to the Universal Declaration of Human Rights. Disponível em: http://unesdoc. unesco.org/images/0007/000748/074816eo.pdf\#48063. Acesso em: jun. 2018. 
Para publicar na Revista de Direito Internacional, acesse o endereço eletrônico www.rdi.uniceub.br ou www.brazilianjournal.org.

Observe as normas de publicação, para facilitar e agilizar o trabalho de edição. 